\title{
THE CONVENTIONAL FACILITIES REQUIREMENTS FOR THE SNS LINAC *
}

\author{
P. Tallerico, M. Crow, A. Guthrie, G. Johnson ${ }^{\dagger}$, J. Schubert ${ }^{\dagger}$, \\ Los Alamos National Laboratory, Los Alamos, NM 87545, USA \\ ${ }^{\dagger}$ Oak Ridge National Laboratory, Oak Ridge, TN 37830, USA
}

\begin{abstract}
The Spallation Neutron Source (SNS) linac has a high gradient and $2 \mathrm{MW}$ of beam power, and it therefore requires substantial RF power and cooling. There are 94 klystrons in its RF system, a large number for a proton linac. The optimization process and logic that lead to the klystron, transmitter, and power supply sizes is discussed. We also describe the requirements for building and tunnel area, electrical power, and water for this system. The trade-off decisions between low capital cost, low operating cost, and good maintainability are described.
\end{abstract}

\section{INTRODUCTION}

When a new major high-power accelerator is being designed, one quickly finds that the conventional facilities of buildings, other civil engineering improvements, electrical power, and cooling water can easily use 25 to $30 \%$ of the total project budget. We describe the measures taken on the SNS project to contain the conventional facilities costs, yet still provide a workable, nearly optimized, facility for the linac and its associated equipment. The linac RF system is described in a companion paper $^{1}$, and it is comprised of seven $2.5 \mathrm{MW}$ klystrons at $402.5 \mathrm{MHz}$, six 5.0 MW klystrons at 805 $\mathrm{MHz}$, and $81550 \mathrm{~kW}$ klystrons at $805 \mathrm{MHz}$ for the superconducting portion of the linac. The klystron efficiencies are 58, 55, and $63 \%$, respectively. The nominal duty factor is $6 \%$, and the powers given are peak. The total installed RF power is $92 \mathrm{MW}$ peak, and $5.5 \mathrm{MW}$ average. In addition, there is a large accumulator ring, a target, a neutron experimental hall, and office buildings, so the SNS does require large amounts of cooling, power, and space.

\section{FACILITY LAYOUT}

For the klystron and front-end buildings, repeated floor plan layouts were made, along with many cross sections. The first layouts were based on vendor's conceptual designs of the equipment, and as the designs were refined, the layouts were changed to include the usually larger equipment. In the plan view, the basic problem is to place the electronic equipment in a minimum-size building to satisfy all safety, maintainability, and assembly requirements. After several redesigns, meetings, video conferences, and discussions, a building width of 30 feet and a height of 24 feet were agreed upon. There is also a front end building that houses the ion source, RFQ,

*Work supported by the Office of Basic Energy Science of the US Department of Energy, and by Oak Ridge National Laboratory. medium energy beam transport system, and the first drift tube linac (DTL) tank. This building is 11000 square feet in size, and will not be discussed further in this paper. Similar interactions and design iterations were necessary to determine the optimal size of the linac tunnel.

\subsection{Linac Tunnel Layout}

The linac output energy is $1000 \mathrm{MeV}$, so shielding between the linac and the outside world is required. Shielding calculations based on the expected maximum loss of $1 \mathrm{nA} / \mathrm{m}$ resulted in 15 feet 10 inches of earth around the linac tunnel, where the accelerator resides. This tunnel floor is 9' lower than the klystron building floor. The tunnel dimensions are 14' wide by 10' high, which is the absolute minimum required. The length of the linac tunnel is 1056 feet, which allows space for more cryomodules for an energy upgrade to $1.3 \mathrm{GeV}$. The tunnel cross section is so tight at the low-energy portion that notches had to be built into the tunnel walls for the DTL waveguides. This is because the DTL waveguide (at $402.5 \mathrm{MHz}$ ) is WR-2100, which is 21 inches on the broad side. Bends and elbows in this waveguide size are physically large. In the $805 \mathrm{MHz}$ portions of the linac, the waveguide size is WR-1150, and the waveguide components are smaller, so no notches are required in the tunnel walls. The centerline of the accelerator is 50 inches above the tunnel floor, and it is 66 inches from the wall that has the waveguide penetrations. A schematic cross section of the tunnel and the klystron building is shown in Fig. 1 below. The extra space on the left side of the linac permits a special cart to install and remove the linac sections. The trapeze supports on the two sides of the klystron building are for cable trays, while the center trapeze is for the water system. Note that the figure also shows one of the HVAC bays on the right side of the figure. There is a water barrier on the berm covered side of the klystron building that extends over the waveguide chases and over the linac tunnel.

\subsection{Klystron Building Layout}

The converter-modulator ${ }^{2}$ power supply is the integrating element of each cluster of klystrons and the associated electronic equipment. The first converter modulator powers three klystrons, and the remaining converter modulators in the DTL portion of the linac each power two klystrons. The CCL converter modulators each power a single klystron, and in the superconducting section of the CCL, they power 11 or 12 klystrons. The design challenge is to place all the linac equipment into the smallest possible building, and to purchase minimal- 


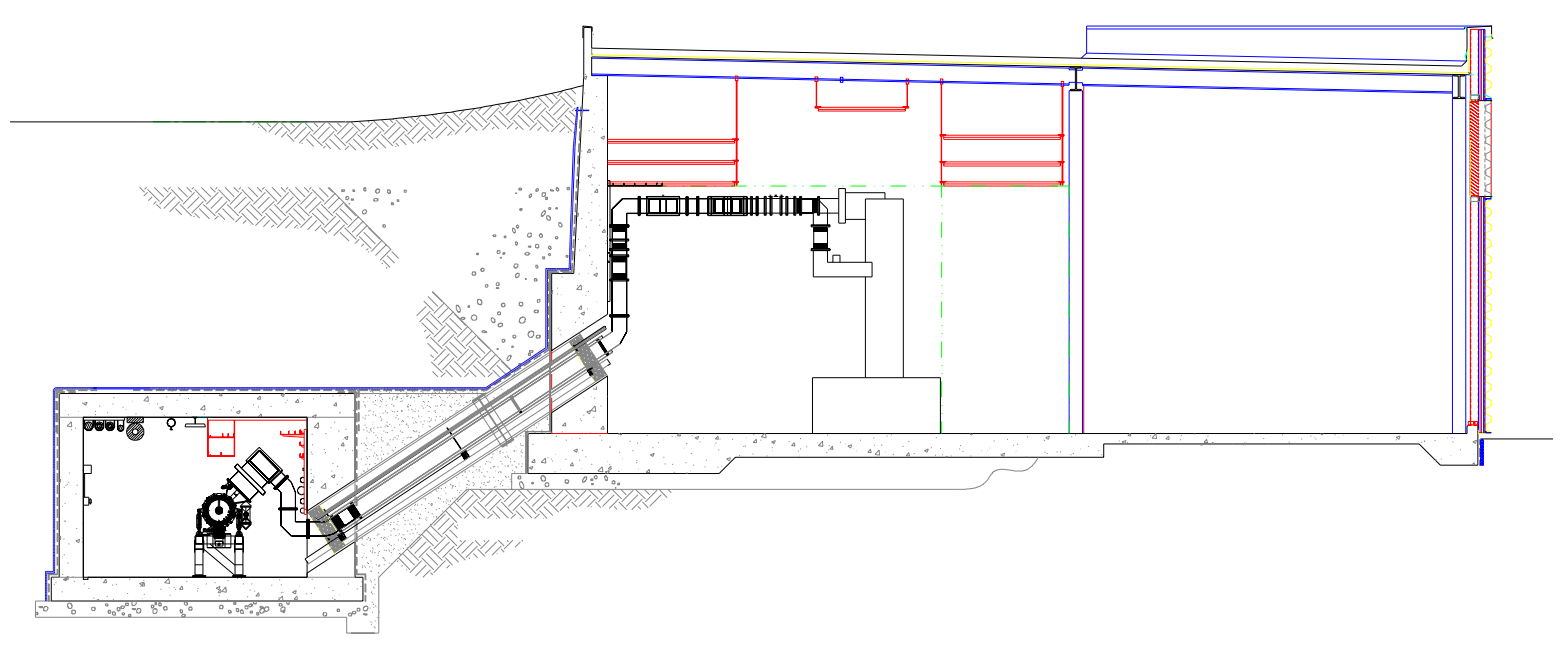

Figure 1: Cross section of the linac tunnel and the klystron building, with an HVAC alcove on the right side.

sized equipment. In both cases, we require that no cost premium be incurred either initially, or in the maintenance phase of the project. The major linac equipment is for RF power, vacuum, cooling, AC power, heating, and ventilating, and air conditioning (HVAC). Fig. 2 is a plan view of a portion of the klystron building. This view is at the first DTL klystron station, and the linac tunnel is on the right.

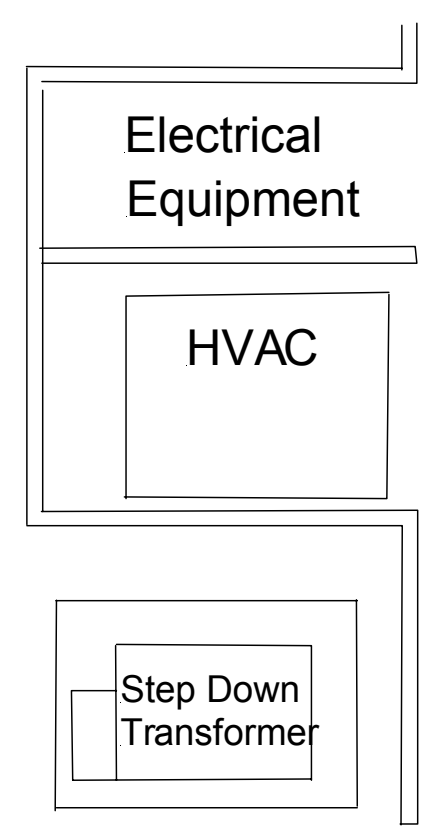

$\sqcap$
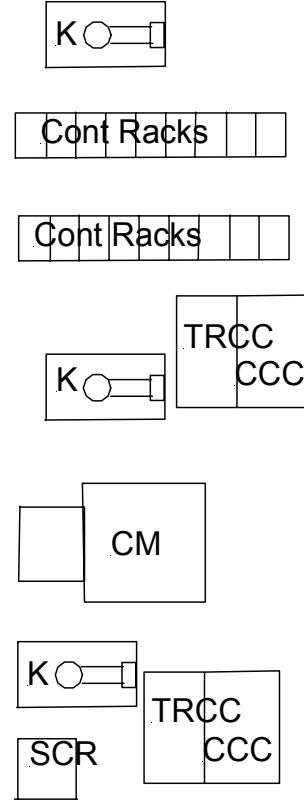

Cont Rack\$

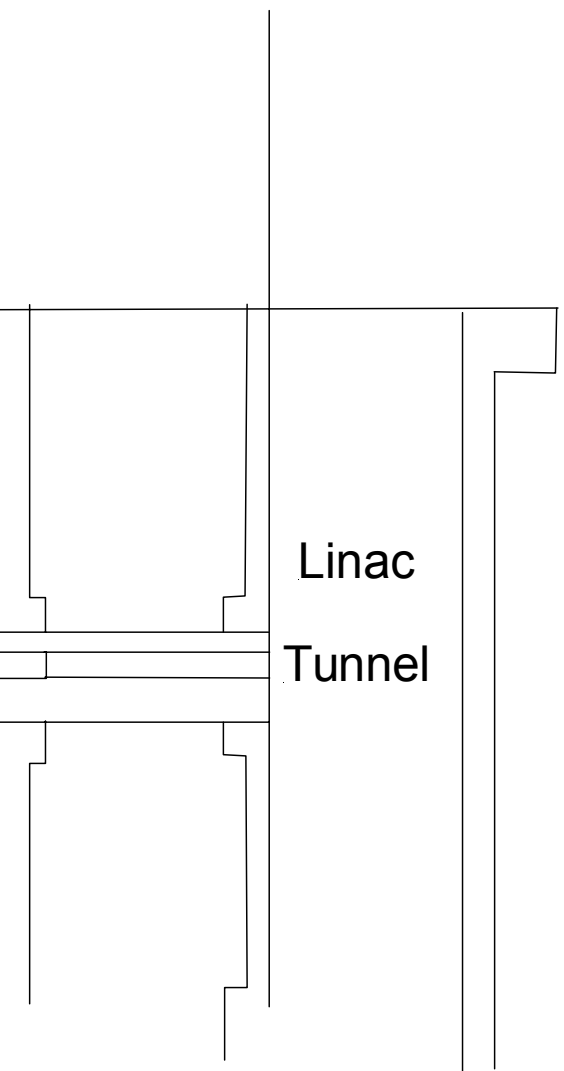

Figure 2: Top view of the linac tunnel and the klystron building. with an HVAC alcove and an electrical equipment alcove on the left side.

In Fig. 2, $\mathrm{K}$ denotes the klystron oil tank, $\mathrm{CM}$ is the converter modulator, TRCC is the transmitter cooling cart, CCC is the cavity cooling cart, and SCR is the SCR power supply that powers the converter modulator. There are two or three rows (depending on the number of 
klystrons) of up to nine control racks per converter modulator, and these racks contain the RF transmitters, controls for the RF system, focus magnet power supplies and their controls, controls for the converter modulator, water and vacuum system diagnostics, diagnostics for the proton beam, and the interfaces to the main SNS control system. The electrical equipment alcove contains the breaker panels for the normal power, clean power for the low level RF controls, and for the uninterruptable power systems. The HVAC unit is the space heater and air conditioning system. Not shown in Fig. 2 are the cable tray systems and the waveguide systems. The waveguide chases are shown connecting the klystron building with the linac tunnel. There are a very few extra chases for signal communication between the klystron building and the linac tunnel, so most of the electrical cables and water pipes must share the waveguide chases with the waveguide. Since several of these cables have significant phase shift with temperature, the waveguide must be water cooled to keep its temperature constant.

The klystron building and linac tunnel temperatures will be maintained between 70 and $90^{\circ} \mathrm{F}$ when the accelerator is operating. This rather large temperature swing is at the limit of temperatures that can be tolerated by the specifications of some of the electrical subsystems, and will consume some of the error budget in the low level RF control system. It will result in some capital cost savings.

There are two 3-ton hoists in the klystron building to allow klystrons to be changed there. There also is an electronics repair building where the klystrons and other high power equipment may be changed and tested prior to installation or re-installation.

\section{UTILITIES}

The total AC power requirement for the initial operation of the linac is $17 \mathrm{MW}$ to the linac tunnel, and the klystron and front end buildings. The operating power for this section of the SNS, including the reactive part, is
19.9 MVA. This does not include the power required for the helium system, which is in a separate building. Aggressive efforts were made to minimize the water system requirements. For example, two or three collectors for the klystrons in the superconducting portion of the machine were placed in series to reduce their total flow requirements. Three collectors in series is a design goal, and two collectors in series is a specification requirement, and we will only know about meeting the goals when the klystrons are finally designed and tested. The total water requirements are 7420 gallons per minute (GPM) of deionized water, $1290 \mathrm{GPM}$ of chilled water, and $315 \mathrm{GPM}$ of water with antifreeze for the low frequency water loads.

\section{CONCLUSIONS}

The linac tunnel, front end, and klystron buildings and their utility systems have been designed to minimize construction costs, but still allow sufficient access for installation and maintenance activities. The bid packages for the tunnel, front end, and klystron buildings are out for bid, and construction is scheduled to start in the fall of this year.

\section{ACKNOWLEDGEMENTS}

The authors thank the contributions the following personnel from the Oak Ridge National Laboratory: John Cleaves and Michael Sandstrom for assistance with the AC power system, and of Thomas McLaughlin, who is in charge of interfaces with the architectural and construction firms.

\section{REFERENCES}

[1] D. Rees et al.,"The RF System Design for the Spallation Neutron Source," PAC '01, Chicago, June 2001.

[2] W. Reass et al., "Spallation Neutron Source (SNS) Polyphase Converter-Modulator for the $140 \mathrm{kV}$ Klystron RF System," PAC '01, Chicago, June 2001. 